\title{
Un caudillo departamental: el jefe político en Córdoba, Argentina (1912-1930)
}

\section{A Departmental Caudillo: The Political Leader in Córdoba, Argentina (1912-1930)}

\author{
Loreta Ruth Giannone \\ (D) https://orcid.org/000-00030235-7313 \\ Instituto de Estudios Históricos \\ Centro de Estudios Históricos "Prof. Carlos S. A. Segreti", Argentina. \\ cehcba@gmail.com
}

Resumen: La presente contribución analiza el funcionamiento de las jefaturas políticas en la provincia de Córdoba durante la coyuntura que se inaugura con la aplicación provincial de la ley Sáenz Peña y finaliza con el golpe de Estado de 1930. Los jefes políticos fueron agentes funcionales a la estructura institucional provincial, siendo el principal canal de comunicación entre la ciudadanía local y la dirigencia política de las altas esferas estatales. Asimismo, tejieron redes de lealtades con los partidos políticos de la provincia aportando un importante caudal de votantes. Primeramente, se indaga en torno a las condiciones previas que permitieron la construcción del liderazgo del jefe político en el ámbito rural, los recursos materiales y eventualmente simbólicos de poder a partir de los cuales configuró su autoridad y su articulación con el Partido Demócrata de Córdoba. En segundo lugar, se analizan las estrategias de interpelación y movilización desplegadas durante las contiendas electorales.

cómo citar: Giannone, L. R. (2021). Un caudillo departamental: el jefe político en Córdoba, Argentina (1912-1930). Secuencia (111), e1791. DoI: https://doi.org/10.18234/secuencia.v0i111.1791

cc $(1)$ Esta obra está protegida bajo una Licencia Creative Commons Atribución-NoComercial 4.0 Internacional. 
Palabras clave: Partido Demócrata; jefes políticos; capital material; capital relacional; movilización electoral.

Abstract: This paper will analyze the workings of the political leaderships in the province of Córdoba during the juncture that started with the implementation at a provincial level of the Sáenz Peña Act and that finished with the coup d'État in 1930. The political leaders were State agents conducive to the provincial institutional structure, and they were the main communication channel between local citizens and the political leaders from higher positions in the state. In addition, they created an allegiance network with the political parties in the province adding an important number of voters. Firstly, there will be an inquiry into the previous conditions that had allowed this political leader to build up the leadership in the rural sector; the financial resources, which eventually became symbols of power from which the leader could establish his authority and his connection to the Democratic Party of Córdoba. Secondly, there will be an analysis of the interpellation and mobilization strategies displayed during electoral contests.

Key words: Democratic Party; political leader; financial capital; relational capital; electoral mobilization.

Recibido: 9 de octubre de 2019 Aceptado: 27 de mayo de 2020

Publicado: 30 de julio de 2021

\section{INTRODUCCIÓN}

T as indagaciones en torno a las características, el funcionamiento y el ca-

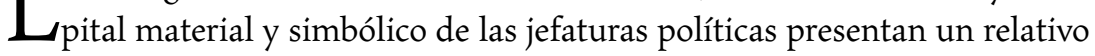
vacío historiográfico, levemente subsanado con algunas investigaciones aisladas que abordan determinados contextos espaciales y periodos históricos. En primer lugar, aquellos estudios que se proponen analizar el proceso de configuración del Estado a través de sus actores intermedios como canales de comunicación entre el poder político central y los sectores populares, en el marco de un proceso de apropiación y legitimación de su poder a escala 
local y las múltiples articulaciones que se operan en diversas escalas del poder (nacional-provincial-municipal). Romana Falcón $(1992,1998,2015)$ ha indagado en torno a la configuración del Estado nacional mexicano a través de la incorporación de la figura del jefe político como eslabón en ese proceso de estructuración, las tensiones, resistencias y estrategias de negociación impulsadas por los sectores populares, o sea, incluyendo la mirada de los de abajo en su propio análisis.

Siguiendo con México, Estefany Vilchis Salazar (2012) examina el funcionamiento del jefe político en la administración pública del Estado de México, destacando continuidades y transformaciones en las leyes estatales que rigieron sus atribuciones, funciones y jurisdicciones. El trabajo de Francisco Javier Delgado Aguilar (2004) explica el proceso político-institucional que originó el establecimiento del sistema de jefaturas políticas en México a principios del siglo xix. Se describen tanto los principales ordenamientos legales de la época (constituciones, decretos, leyes orgánicas) como el contexto político que imperó en el país durante las décadas de 1810 y 1820, factores que propiciaron la creación de una figura de carácter centralizador como el jefe político.

En Argentina, el pionero estudio de Marta de la Cuesta Figueroa (1977) indaga en torno a las atribuciones y funciones de estas figuras intermedias en Salta desde su instalación por la Constitución salteña de 1855 hasta principios del siglo xx, destacando sus vínculos con el gobierno provincial y municipal, respectivamente. Por su parte, Marta Bonaudo (2003) analiza la figura del jefe político en Santa Fe como instancia clave en la legitimación del poder local, previo al reordenamiento de los municipios, lo que lo lleva a competir, en palabras de la autora, con este poder local.

Una segunda línea de indagación propone estudiar el clientelismo político como parte inherente al funcionamiento, a las prácticas de las jefaturas políticas y como instancia clave en la consolidación del poder estatal a escala regional. De este modo, el trabajo de Norma Pavoni (2016) para Córdoba estudia las funciones, las atribuciones y el capital relacional de los jefes políticos en la coyuntura abierta por la crisis del juarismo de los años noventa y la instalación del sistema democrático provincial con la aplicación de la ley Sáenz Peña. Se indaga en torno a las estructuras partidarias del periodo y sus estrategias de reclutamiento del electorado en el ámbito provincial, en donde estas figuras se convirtieron en eslabones clave de dicho proceso.

Así, Pavoni encauza su trabajo dentro de una línea de indagación ya iniciada por Dolores Béjar (2002), que considera que los procesos de demo- 
cratización, lejos de desalentar el fenómeno clientelístico, activaron nuevos mecanismos clientelares, aumentando la capacidad de maniobra de los caudillos que interpelaban a las bases.

Al margen de la investigación de Pavoni, que se concentra en los vínculos entre estructuras partidarias y jefaturas políticas durante el régimen de dominación oligárquica, llama la atención la escasez de indagaciones que aborden los complejos procesos de articulación de los jefes políticos con las grandes fuerzas mayoritarias durante los primeros años de transición a la democracia, principalmente a través del estudio en torno a las prácticas y estrategias de interpelación y movilización de los electorados.

En este marco, la presente contribución analiza en clave regional y en estrecha vinculación con el complejo entramado social, el funcionamiento de las jefaturas políticas en la provincia de Córdoba durante la coyuntura que se inaugura con la aplicación provincial de la ley Sáenz Peña, y finaliza con el golpe de Estado de 1930. Como actor clave en la estructuración del Estado provincial en el territorio departamental, los jefes políticos fueron agentes estatales funcionales a la estructura institucional provincial, siendo el principal canal de comunicación entre la ciudadanía local y la dirigencia política de las altas esferas estatales. Asimismo, tejieron importantes redes de lealtades con las fuerzas políticas mayoritarias de la provincia aportando un importante caudal de votantes durante las contiendas electorales.

En primer lugar, se indaga en torno a las condiciones previas que permitieron la construcción del liderazgo del jefe político en el ámbito rural, se analizan los recursos materiales y eventualmente simbólicos de poder a partir de los cuales configuró su autoridad entre la población local y su articulación con el Partido Demócrata de Córdoba. En un segundo apartado se analizan las estrategias y las prácticas de cooptación y de coerción configuradas por estos actores como mecanismo de sostenimiento y de reforzamiento de su espacio de control y dominación en el ámbito departamental, haciendo hincapié en las estrategias de interpelación y movilización desplegadas durante las contiendas electorales. 


\section{LAS CONDICIONES MATERIALES Y EL ROL POLÍTICO DE LAS JEFATURAS (1912-1930)}

Aunque se discute el origen ${ }^{1}$ de las jefaturas políticas, estas debían funcionar como una presencia directa del gobierno central en los ayuntamientos, "como una institución intermedia de administración territorial" (Bonaudo, 2003, p. 10). Trasladada a Latinoamérica (por ejemplo, al México independiente), esta refiere a un funcionario que, dado el peso de los municipios en esa realidad, aparece como instancia de mediación entre estos y el gobernador (Bonaudo, 2003, p. 15).

Esta institución fue establecida en algunas provincias argentinas en la segunda mitad del siglo xIx. Córdoba la incorporó en la reforma constitucional de 1870 para la administración, organización y control de cada departamento de campaña. Una de las innovaciones más importantes fue que el jefe político debía "no tener investidura ni grado militar". El poder ejecutivo necesitaba el acuerdo de la Cámara de Senadores para nombrar a los jefes políticos titulares, pero no para removerlos. ${ }^{2}$ En cuanto a los requisitos para su designación, coincidían con aquellos necesarios para ser senador provincial: ser ciudadano, mayor de 30 años y con una renta anual de 1000 pesos fuertes.

El jefe departamental se convirtió, entonces, en el agente directo del gobierno en cada departamento. Allí ejercía la autoridad política, intermediaba entre el poder ejecutivo y los empleados locales, colaboraba con las autoridades judiciales y municipales y comunicaba, en caso necesario, al gobierno con los jefes o comandantes de la Guardia Nacional de esa jurisdicción. Estos y la Policía Departamental quedaron bajo la dependencia de la jefatura política, y entre sus funciones se encontraron las de conservar el orden público, garan-

${ }^{1}$ En un análisis minucioso acerca de la configuración del Estado a finales del siglo xIX a partir del estudio de los prefectos y de los comisarios de la campaña bonaerense, Melina Yangilevich dedica un primer apartado sobre los aportes en torno a la figura del jefe político en México $y$, en tal sentido, menciona la discusión que existe entre los historiadores sobre los orígenes de la institución. Mientras que algunos autores sostuvieron que la figura se originó en la Constitución de Cádiz de 1812 (Mecham, 1986; Vilchis Salazar, 2012), otros historiadores, por el contrario, plantearon que esta institución se vinculaba con las reformas borbónicas, precisamente la Real Ordenanza de Intendentes de 1786 (Delgado Aguilar, 2004; Yangilevich, 2018, pp. 74-75).

${ }^{2}$ De acuerdo con el art. 117, inc. 8 de la Constitución Provincial de 1870, si el poder ejecutivo nombraba jueces políticos interinos durante el receso del Senado, debía dar cuenta de ello en la primera sesión de la Cámara, solicitando la designación en propiedad de los mismos (Cucchi, 2015, p. 223). 
tizar la ejecución de leyes y reglamentos de justicia y proteger a las personas y la propiedad pública y privada. Por otra parte, debía hacer efectiva la ley de enrolamiento en el territorio bajo su dependencia, capturando y remitiendo a la capital a quienes no se hubiesen enrolado en la Guardia Nacional en tiempo oportuno (Cucchi, 2015, p. 230).

A partir de 1932, las jefaturas políticas pasaron a estar bajo inspección directa del Ministerio de Gobierno, lo que en la práctica significaba el envío, la tramitación y la liquidación de planillas de sueldos y gastos, la remisión de una copia de altas y bajas producidas en el personal y la denuncia contra cualquier autoridad, al Ministerio de Gobierno. ${ }^{3}$

La vinculación de las jefaturas políticas con el Estado provincial se visualizaba por medio de la realización de memorias que anualmente elevaban estos agentes intermedios a los gobernadores y los reiterados pedidos de material y personal, fundamentalmente de policía, necesarios para el desenvolvimiento y el bienestar de los departamentos. El constante reclamo de las autoridades departamentales de machetes, comisarios y policías evidenciaba los problemas de seguridad que atravesaban estas regiones, donde el poder estatal ejercía un control relativo.

Los departamentos localizados en la serranía cordobesa y en el noroeste de la provincia, como Ischilín, San Alberto, Pocho y Minas, ${ }^{4}$ presentaban estos inconvenientes, sumados a la falta de infraestructura edilicia y de obras públicas destinadas al alumbrado, servicio de agua potable, etc. ${ }^{5}$ Aun así, los pedidos de intervención del gobierno provincial en las problemáticas de las

3 "Inspección de jefaturas políticas depende ahora del Ministerio de Gobierno", La Voz del Interior, 23 de noviembre de 1932, p. 4, C6 y 7.

${ }^{4}$ Esta región de la provincia estaba conformada por un entramado geográfico (noroeste y serranía cordobesa) caracterizado por una dinámica poblacional y socioeconómica relativamente homogénea, manifestando un claro retroceso en sus variables de población y de economía. No sólo concentraba el menor porcentaje de la población, que por el flujo de las migraciones internas se trasladaban al sudeste provincial, sino que las actividades económicas atravesaban por un periodo de franco estancamiento. Sin embargo, resulta preciso mencionar, dentro del conjunto, algunos rasgos distintivos que permite comprender la política de construcción de obras públicas del Estado. Siguiendo el análisis de la prensa oficialista, esta caracterizaba a la región que se extendía desde el Dique San Roque hasta Cruz del Eje como el primer atractivo turístico del país (Giannone, 2014, 2018).

${ }^{5}$ Jefaturas Políticas. 1916. Fondo Gobierno. Tomo 24, f. 609; Jefaturas Políticas. 1921. Fondo Gobierno. Tomo 38, f. 360; Jefaturas Políticas. 1918. Fondo Gobierno. Tomo 38, f. 360; Jefatura Política. 1921. Fondo Gobierno. Tomo 1, f. 602. Jefatura Política. 1923. Fondo Gobierno. Tomo 1, f. 543. Archivo Histórico de la Provincia de Córdoba (en adelante AHPC), Argentina. 
localidades del interior no se limitaban a los departamentos mencionados, siendo Tercero Abajo y San Justo algunos de los casos que revelan ciertas problemáticas vinculadas a la falta de obra pública y fundamentalmente de personal policial.

En 1916 el jefe político de Tercero Abajo detallaba la falta de caminos y de servicios de algunas ciudades de su departamento. Al respecto, Ceballos destacaba: "En el plano se ven los numerosos pantanos que hay que rellenar, los otros puentes y alcantarillas necesarias; es elocuente el número para demostrar el grado de abandono al que se ha dejado llegar a Tercero Abajo" $\mathrm{y}$ continuaba señalando los sujetos políticos que intervenían en la resolución de las problemáticas expuestas, obras que había comenzado a realizar el radicalismo. $^{7}$

En San Justo, enviaba un telegrama dirigido al gobernador provincial informando sobre el estado de deterioro de la policía y sus armamentos y mencionaba la importancia que el departamento tenía en términos de desarrollo productivo: "resulta necesario mejorar la remuneración del personal como medio indispensable para cubrir los gastos que exige la vida; la importancia adquirida por el departamento en el desarrollo comercial, industrial, agrícola y ganadero". ${ }^{8}$

Por su parte, las memorias informaban el estado en que el departamento se encontraba en materia administrativa, económica, social y los progresos que en estas áreas habían realizado los jefes políticos salientes. Las memorias elevadas por las autoridades departamentales revelaban las condiciones socioeconómicas y productivas que caracterizaban a la región, ${ }^{9}$ la situación de la policía, de las agrupaciones políticas, el estado económico, sanitario, social, los caminos públicos, edificios administrativos, escolares, ferrocarriles, entre

${ }^{6}$ Jefaturas Políticas. 1916. Fondo de Gobierno. Tomo 24, f. 609. AHPC, Argentina.

7 Jefaturas Políticas. 1916. Fondo de Gobierno. Tomo 24, f. 609. AHPC, Argentina.

8 Jefaturas Políticas. 1927. Fondo Gobierno. Tomo 41, f. 225. AHPC, Argentina.

9 Teniendo en cuenta la diversidad de espacios regionales abordados en este artículo, se recupera la noción de región de Pirre Vilar que construye el espacio regional a partir de tres ideas básicas e íntimamente vinculadas, ideas que si bien remiten a la delimitación geográfica la excede y la trasciende. En primer lugar, el espacio, teniendo en cuenta un universo de análisis con cierto grado de homogeneidad relativa. En segundo lugar, el tiempo, ya que se establece una periodización acorde con el objeto de estudio y, en tercer lugar, el marco institucional, en este caso, las jefaturas políticas como autoridades superiores que tenían injerencia a escala departamental (Vilar, 1976, pp. 37-37). 
un abanico amplio de actividades realizadas para el desarrollo físico e intelectual de los niños y niñas. ${ }^{10}$

Finalmente, la reunión anual de los jefes políticos con las principales autoridades departamentales y provinciales era otra de las formas de vinculación entre ambas instancias del poder político. Estas conferencias, destinadas al tratamiento de diversos temas relativos al funcionamiento de los departamentos, sus mecanismos de elección, las necesidades materiales que atravesaban las jurisdicciones, contaban con un detallado programa protocolar que incluía un acto de apertura con discursos preparados por el gobernador, los intendentes municipales, legisladores de ambas Cámaras, el ministro de Gobierno y algunos jefes políticos caracterizados del interior provincial. Los principales corresponsales de la prensa provincial y nacional asistían a estas conferencias no sólo para informar a sus respectivos diarios sobre los sucesos del evento, sino además como invitados. ${ }^{11}$

Ahora bien, un elemento ponderativo que permite explicar el fuerte liderazgo consolidado por los jefes políticos en el ámbito departamental resulta de su perfil socioeconómico y fundamentalmente de su capital relacional. Además de constituirse como "máxima autoridad departamental", algunos jefes políticos eran estancieros, otros médicos, otros contaban con fuertes redes de lealtades a través de su liderazgo en las agrupaciones departamentales. Este sólido capital relacional y económico personal les permitía ser intermediarios culturales y sociales clave entre la sociedad y el Estado. ${ }^{12}$

${ }^{10}$ Jefaturas Políticas. 1924. Fondo Gobierno. Tomo 39, f. 478; Jefaturas Políticas. 1927. Fondo Gobierno. Tomo 42, f. 408; Jefaturas Políticas. 1928. Fondo Gobierno. Tomo 7, f. 666. AHPC, Argentina.

${ }^{11}$ Municipalidades. 1927. Fondo Gobierno. Tomo 34, f. 421; AHPC, Argentina; "Primera Conferencia de Jefes Políticos, se inaugurará mañana”, El País, 13 de febrero de 1927, p. 7, C1-5.

${ }_{12}$ A través de las circulares enviadas al Ministerio de Gobierno, las memoria elevadas por los jefes políticos, entre otra documentación variada, se han identificado a catorce jefes políticos: 1. Pocho: Próspero Cáceres; 2. Cruz del Eje: Manuel Bustos; Unión: José Bianchi; Totoral: Manuel Torres Cabrera; Río IV: Teniente Coronel Oliyamburu, Florencio Arrázola, Carlos Sarandón; Ischilín: Quinteros; General Roca: Eduardo Rodríguez; Río Seco: Saravio; Tercero Abajo: Mariano P. Ceballos; San Justo: Ezio Bellone; Colón: Jordán Maldonado (h); Calamuchita: Miguel Astrada. Se consiguió reconstruir el perfil socioeconómico de algunos de los jefes políticos de la muestra. Entre ellos: Maldonado Jordán (h), quien pertenecía a la UCR personalista. Se destacó como estanciero, poseía un establecimiento de ganadería en Río Ceballos. Miguel Astrada pertenecía a la familia de los Astrada en Calamuchita y también poseían importantes estancias en el departamento y en otros aledaños. Poseía un establecimiento de ganadería en Bell Ville (Departamento Unión), era propietario rural en Calamuchita y Marcos Juárez. Cáceres, pertenecía a la UCR antipersonalista y era chacarero y procurador. Mariano P. 
Tal como analiza Eric Wolf (1990, p. 10), los mediadores políticos eran eslabones de una cadena que ligaban la comunidad con el Estado central. De este modo, los vínculos políticos informales revelaban la particular manera en que se construía la articulación entre diferentes niveles de la acción estatal. Durante el periodo abordado en este artículo, no todos los jefes políticos configuraron su poder a través de su capital económico y del control que este le permitía ejercer sobre la población local; por el contrario, en reiteradas ocasiones eran depuestos por la autoridad central, lo que evidenciaba la relativa autonomía y el liderazgo en el interior de la provincia. ${ }^{13}$

Durante la campaña electoral en el marco de la elección para gobernador del 17 de noviembre de 1912, el carcanismo ${ }^{14}$ reiteraba en el plano discursivo la necesidad de ejercer un mayor control en los departamentos de la campaña a través de la designación de "buenos jefes políticos" capaces de recuperar el desenvolvimiento normal de las instituciones, garantizar la paz, el orden y la seguridad de los habitantes en los territorios de campaña: "Un buen jefe político es una garantía para que los jueces hagan buena justicia, para que los receptores perciban con equidad y con honradez la renta, para que los comisarios mantengan el orden y cuiden de la seguridad individual." ${ }^{15}$ Las denuncias de los ciudadanos acerca de la intromisión de estos agentes estatales en los asuntos electorales se reiteraban.

Ante la proximidad de cada elección, el gobierno provincial enviaba circulares a las autoridades departamentales sobre las medidas que tomaría

Ceballos poseía redes de lealtades propias lo que le permitió alternar su apoyo al radicalismo y al Partido Demócrata. Este dirigente no poseía un sólido capital económico vinculado a la actividad agropecuaria, sino que sus vínculos con la población se derivaban de su profesión de médico. Finalmente, Saravio era un cura vinculado políticamente al carcanismo. Jefaturas Políticas. 1908. Fondo Gobierno. Tomo 10, f. 78; Jefaturas Políticas. 1909. Fondo Gobierno. Tomo 3, f. 50; Jefaturas Políticas. 1914. Fondo Gobierno. Tomo 21, f. 409; Jefaturas Políticas. 1915. Fondo Gobierno. Tomo 9, f. 79; Jefaturas Políticas. 1918. Fondo Gobierno. Tomo 1, f. 509, tomo 2, f. 302 y tomo 3, f. 39; Jefaturas Políticas. 1919. Fondo Gobierno. Tomo 19, f. 17; tomo 20, f. 37; tomo 21, f. 307; tomo 22, f. 59. AHPC, Argentina.

13 "La jefatura política", La Nación, 20 de enero de 1916, p. 7, C4; "Jefatura Política de Marcos Juárez. Designación del Sr. Zambianchi”, La Voz del Interior, 21 de agosto de 1919, p. 4, C3; "Jefatura Política del departamento de Colón", La Voz del Interior, 2 de diciembre de 1920, p. 5, C2 y 3; "Fue intervenida la Jefatura de Totoral", La Nación, 23 de febrero de 1930, p. 15, C5; "Córdoba. Nombramiento de jefes políticos", La Nación, 16 de febrero de 1930, p. 15, C2.

${ }^{14}$ Remite a la caracterización que se hace en referencia al por entonces gobernador de la provincia de Córdoba, Ramón J. Cárcano, que gobernó por el Partido Demócrata en dos oportunidades, primero entre 1912 y 1916 y, posteriormente, entre 1924 y 1928.

15 “Actualidad. Jefes Políticos", Los Principios, 4 de junio de 1913, p. 3, C5 y 6. 
frente a una eventual intervención en las campañas electorales: "este gobierno reprimirá con energía todo acto conducente a desvirtuar la naturaleza de los comicios próximos, o a coartar el libre ejercicio de cualquiera de los derechos que para tal efecto deben ejercitar los ciudadanos de la provincia". ${ }^{16}$

No obstante, a partir de los años veinte las elites estatales del gobierno central manifestaban su desacuerdo con las funciones de las jefaturas políticas. En 1923, la Convención Constituyente de Córdoba se proponía reformar -además de otros artículos- el régimen departamental, a través de su supresión. ${ }^{17}$

En 1925, el diario La Voz del Interior, reproducía la circular que el gobierno provincial enviaba a los departamentos, en donde destacaba las características de los jefes políticos, sus "excesos" y su escasa responsabilidad en los asuntos que le competían: "desde antiguo [...] se consideran dueños y señores de un departamento, al que manejan como se podría manejar un feudo, en el cual ellos tienen la facultad omnímoda de rodearse de colaboradores sin más idoneidad que el grado de adhesión que manifiestan no al gobierno [...] sino al funcionario que en cada zona inviste el poder supremo local". ${ }^{18}$

En reiteradas oportunidades el gobierno provincial intervenía las jefaturas políticas para deponer al jefe y a sus agentes principales, reorganizando el departamento con nuevas autoridades. ${ }^{19}$

Dos razones principales explicaban esta relativa autonomía de los jefes políticos. En primer lugar, la posición de importantes sectores del arco político provincial que propugnaban por la eliminación de esta figura política, entre ellos los dirigentes que tenían intereses políticos-partidarios en la capital y el Partido Socialista. ${ }^{20}$ En segundo lugar, y vinculado con lo anterior, las reiteradas denuncias de la población local en torno a los "atropellos", la

16 "Circular a los jefes políticos", La Prensa, 1 de marzo de 1918, p. 5, C5; "Circular enviada por el Ministerio de Gobierno a los jefes políticos”, La Prensa, 5 de febrero de 1928, p. 16, C1.

17 "Córdoba. Convención Constituyente", La Prensa, 1 de mayo de 1923, p. 7, C5.

18 "La circular del ministro de Gobierno", La Voz del Interior, 22 de agosto de 1925, p. 8, C1 y 2.

19 "Reorganización del personal de las jefaturas políticas", La Nación, 30 de enero de 1931, p. 11, C6 y 7; "Córdoba. El Poder Ejecutivo intervino las jefaturas políticas de Marcos Juárez y Río IV”, La Nación, 16 de febrero de 1930, p. 15, C2.

${ }^{20}$ En 1923 el gobierno de Julio A. Roca había convocado a una convención reformadora de la Constitución para reformar, entre otros artículos, el régimen departamental. Entre algunos de los argumentos que esgrimían los convencionales en contra de esta figura se destaca el anacronismo de los jefes políticos y su falta de interés en los problemas de las localidades. Diario de Sesiones de la Honorable Convención Reformadora de la Constitución, 1923. 
utilización sistemática de prácticas de coacción ${ }^{21}$ y su escasa intervención en los asuntos públicos ${ }^{22}$ cooperó con tal medida por parte del gobierno provincial, quien sostenía, a propósito de su selección, que "Se procurará que los nombramientos de los jefes políticos constituyan una garantía para los vecindarios, en cuanto a honestidad y condiciones morales de las personas que desempeñarán esas funciones. ${ }^{23}$

\section{EL ROL DE LOS JEFES POLÍTICOS DURANTE LAS CAMPAÑAS ELECTORALES: PRÁCTICAS Y ESTRATEGIAS DE RECLUTAMIENTO Y MOVILIZACIÓN}

A pesar de las fuertes críticas al régimen departamental, la creciente preocupación de los partidos por incrementar las bases electorales, fundamentalmente en un contexto de ampliación del sufragio y de crecimiento exponencial del electorado, ${ }^{24}$ planteaba la necesidad de reforzar los vínculos con estos jefes departamentales: "son la condición suprema del buen o del mal gobierno [...] en política electoral la ciudad no pesa nada en comparación con lo que pesan los departamentos". ${ }^{25}$

La relevancia de los jefes políticos en la lucha electoral responde al importante rol electoral que desempeñaban, particularmente en los departamentos donde no se había constituido el poder municipal. Al respecto, Marta Bonaudo (2003), para el caso de Santa Fe, el cual podemos hacerlo extensivo para Córdoba ${ }^{26}$ dada las similares características de ambas provincias en

21 "Actualidad. La policía de Río IV. Los Partidos Departamental y el Comercio, denuncian al jefe político, a los comisarios y a los agentes", Los Principios, 6 de marzo de 1912, p. 3, C5; "En Cruz del Eje. Un ciudadano abofeteado por el jefe político", La Voz del Interior, 18 de julio de 1917 , p. 4, C3 y 4.

22 "Circular a los jefes políticos", La Prensa, 1 de marzo de 1918, p. 5, C5; "Cosas de Totoral”, La Voz del Interior, 9 de septiembre de 1920, p. 4, C6 y 7; "La jefatura de Ischilín”, La Voz del Interior, 23 de agosto de 1925, p. 10, C3 y 4.

23 "Córdoba. El problema de las jefaturas políticas va a ser encarado", La Nación, 21 de febrero de 1932, p. 15, C4.

${ }^{24}$ El número de empadronados creció de 96489 durante las elecciones de diputados nacionales en 1912 a 139059 en 1916 (Tercer Censo Nacional, 1916).

25 “Actualidad. Los jefes políticos”, Los Principios, 4 de junio de 1913, p. 3, C5 y 6.

${ }^{26}$ Eran constates los reclamos de los "vecinos notables" (comerciantes, propietarios rurales) por la conformación de comisiones de fomento o administradoras en las localidades del interior provincial. Estas unidades organizativas se convirtieron, con el correr de los años, en 
relación con la tardía conformación de entidades municipales, sostiene que la jefatura precedió a la emergencia de los municipios, convirtiéndose estos en un espacio cuya jurisdicción va a competir a medida que se avance en el reordenamiento institucional: "El Jefe Político actuaba con un alto grado de discrecionalidad en una borrosa frontera entre lo político y lo jurídico, pretendiendo consolidar un proyecto de dominación" (Bonaudo, 2003, p. 25). Allí solía estar a cargo de la inscripción en el registro cívico, así como de la designación de las autoridades que presidían las mesas instaladas con ese fin, y en ocasiones de la custodia de las actas hasta su remisión a la misma capital (Cucchi, 2015, p. 215).

Del relevamiento que se ha realizado en el fondo Gobierno, concentrado en el Archivo Histórico de Córdoba, se observa de qué manera los "vecinos notables" reclamaban al poder provincial un conjunto de servicios públicos relegados en sus localidades. Son innumerables los pedidos de caminos, policías, servicios de agua potable, servicio de mensajería, etc. En estos procesos de "demanda" de la población local, se destacó un complejo entramado de vínculos que configuraron la autonomía municipal, prescindiendo de los jefes políticos departamentales, lo que llevó a la disputa entre ambos eslabones políticos por la monopolización de la autoridad local. ${ }^{27}$

La creciente influencia de los jefes políticos en el espacio rural, aunado a un escenario electoral que llevaba a requerir de sus estrategias electorales para cooptar votantes, incidió en que los dirigentes del Partido Demócrata aprovecharan los recursos previos con los que contaba este sujeto político para negociar los términos de una elección.

Las prácticas de coacción y clientelares, quizá más marcadas en el noroeste de la provincia, coincidían con aquellas estrategias dirigidas a convencer al elector. Entre 1918 y 1928 fueron constantes en algunos departamentos del noroeste de la provincia, como Ischilín, Cruz del Eje y Pocho, la realización de banquetes en aristocráticos clubes sociales, en los que participaban los

municipios autónomos. Fondo Municipalidades. 1917. Tomo 13, f. 528. Jefaturas Políticas. 1917; Fondo Gobierno. Tomo 20, f. 34. Jefaturas Políticas. 1917; Fondo Gobierno. Tomo 22, f. 427. Municipalidades. 1917. Tomo 23, f. 771; tomo 10, f. 410; Tomo 14; tomo 16, tomo 22. AHPC, Argentina.

${ }^{27}$ Municipalidades y Comisiones de Fomento. 1908. Fondo Gobierno. Tomo 6, f. 358; Solicitudes y Asuntos Diversos. 1908. Fondo Gobierno. Tomo 9, f. 500. AHPC, Argentina; Giannone (2018, p. 104). 
dirigentes del partido demócrata, vecinos de las localidades e invitados que representaban los intereses comerciales e industriales de los departamentos. ${ }^{28}$

A diferencia de los departamentos del noroeste donde los demócratas obtenían victorias contundentes (Giannone, 2014, p. 213), en el este y sudeste de Córdoba ${ }^{29}$ las redes de lealtades con los caudillos eran más inestables, lo que dificultaba el triunfo electoral en estas localidades. Asimismo, a partir de la segunda mitad de la década de 1920, la incorporación definitiva de Mariano P. Ceballos (caudillo del departamento Tercero Abajo a través de su ocupación como jefe político) a las filas del Partido Demócrata, les permitió a los conservadores contar con un no desdeñable caudal de votantes en esta región.

En 1919, a propósito de la elección a la diputación nacional, Mariano P. Ceballos, jefe político del departamento Tercero Abajo, renunciaba a su cargo para dedicarse a las actividades electorales a favor del Partido Demócrata. Aunque la posición de Ceballos como dirigente político de segunda línea que contaba con redes de influencias y de lealtades propias le permitía mantener una posición ambivalente en su apoyo a los partidos políticos, ${ }^{30}$ la base de clientela configurada por su liderazgo en el departamento fue un incentivo para el Partido Demócrata en la concertación de alianzas con otras personalidades de la región. Hacia mediados de la década de 1930, la dirigencia demócrata visitaba el departamento durante cada coyuntura eleccionaria, aplicando un programa detallado de actividades electorales, no sólo dirigido a las principales personalidades políticas, sino, además, hacia los votantes populares. ${ }^{31}$

El control de la situación departamental por el jefe político lleva a comprenderlo y asimilarlo como una figura con poder y autoridad que intercam-

28 “Un banquete demócrata”, Los Principios, 20 de julio de 1918, p. 3, C5; "Pocho. Un banquete para el jefe político", La Nación, 18 de agosto de 1919, p. 2, C4 y 5; "En Ischilín los demócratas realizan un banquete a la nueva autoridad", La Voz del Interior, 15 de abril de 1920, p. 2, C4; "Un banquete al jefe político de Pocho", Los Principios, 20 de enero de 1921, p. 2, C5; "El banquete al jefe político", La Prensa, 4 de septiembre de 1922, p. 5, C2; "Un jefe político", La Voz del Interior, 12 de julio de 1923, p. 4, C5; "El banquete al jefe político de Pocho", Los Principios, 23 de mayo de 1924, p. 5, C3; "En las sierras", Los Principios, 21 de julio de 1925, p. 2, C5; "Cruz del Eje. Se dará un banquete al jefe político”, El País, 9 de octubre de 1928, p. 3, C4 y 5.

${ }^{29}$ Conformado por los departamentos que consiguieron insertarse plena y exitosamente al modelo económico dominante, lo que se tradujo en un significativo crecimiento económico.

30 "Jefatura Política de Tercero Abajo", La Voz del Interior, 14 de octubre de 1919, p. 4, C5.

31 "La Jefatura de Tercero Arriba. Renuncia del señor Mayorga", La Voz del Interior, 6 de junio de 1917, p. 4, C3 y 4; "Se encargará la jefatura política de Tercero Abajo al señor Julián Nobregas", La Voz del Interior, 2 de febrero de 1935, p. 7, C3 y 4; "Designóse jefe político del departamento Tercero Abajo”, La Voz del Interior, 8 de febrero de 1935, p. 7, C7. 
biaba un conjunto de bienes materiales y favores para conseguir votantes y acceder así a las estructuras partidarias.

En la estructura intermedia de la red clientelar, ${ }^{32}$ el nepotismo se reproducía como parte de una estrategia de intercambio de favores capaz de incorporar a los miembros de toda una familia en los principales puestos de la estructura microinstitucional. La red clientelar funcionaba a través de la designación de jefes políticos, comisarios, jueces y receptores relacionados entre sí por medio de vínculos de parentesco. ${ }^{33}$ En este sentido, hijos, sobrinos y parientes cercanos del jefe político eran designados en cargos públicos de instancia local y provincial respectivamente, lo que en ocasiones provocaba acciones violentas por parte de aquellas fuerzas políticas que cuestionaban la designación del funcionario. En el departamento Río Seco (localizado en el norte de la provincia de Córdoba), la designación del sobrino del jefe político como senador provincial dio lugar a una reunión política que ocasionó un hecho de sangre. ${ }^{34}$

La promesa de empleo, de servicios de obras públicas para el desarrollo local y regional (escuelas, puentes, etc.) hasta la destitución de algún juez de paz y/o comisario era un recurso efectivo de propaganda electoral sobre ciertos sectores. Dar y prometer se convertía en una estrategia de campaña electoral: "el jefe político ofrece empleos y muy especialmente puestos en las escuelas, todo esto bajo la mano protectora del Dr. Garzón Maceda, quien escribe a sus íntimos haciendo llegar a Jacinto Palacios y otros de la familia Montel promesas halagadoras". ${ }^{35}$

Como se observa en la cita aludida, el jefe político era además un mediador que debe atraer a sectores independientes ("sus iguales" y otros que no lo eran tanto), con promesas, generando esperanzas y despertando la confianza de los eventuales seguidores o partidarios. Relaciones personales basadas en la amistad y el parentesco eran las bases de la formación de grupos políti-

32 Partiendo del análisis que realiza Pavoni (2000) acerca de las relaciones clientelares configuradas por el jefe político en el ámbito departamental, en esta ponencia se analiza esa relación clientelar desde una red que reconoce la vinculación entre dirigentes políticos del Partido Demócrata y jefes políticos y entre estos últimos y los "potenciales votantes". Esa red clientelar incluye el intercambio de bienes y favores entre los sujetos intervinientes, intercambio que se sostiene a través de los fuertes vínculos consolidados históricamente entre los jefes políticos y los electores.

33 "Todo un pueblo", La Voz del Interior, 9 de febrero de 1912, p. 6, C2 y 3; "Las elecciones en Totoral”, La Voz del Interior, 31 de marzo de 1914, p. 2, C6 y 7.

${ }^{34}$ Jefaturas Políticas, 1914. Fondo Gobierno. Tomo 21, f. 575. AHPC, Argentina.

35 “Las vacantes legislativas", Los Principios, 24 de noviembre de 1918, p. 2, C3. 
cos "informales" más amplios y formalmente conflictivos que se coaligaban en circunstancias electorales (Vidal y Ferrari, 2000, p. 29).

La presencia de los hombres de la campaña que lideraban clientelas de potenciales electores para la fuerza política conservadora fue una práctica reproducida en el mundo rural. La historiografía local ha destacado su mayor incidencia en los departamentos del norte de Córdoba, siendo San Javier, Pocho, Calamuchita, Río Seco, y toda la región del oeste de la provincia, los ejemplos más claros de este predominio, no sólo por la existencia de una agrupación política independiente -conocida como Partido Departamental-con arraigo en la población de la zona, sino porque la misma respondía a las directivas de diferentes caudillos que controlaban las localidades de la región. ${ }^{36}$

Sin embargo, y a pesar del fuerte liderazgo que poseían los jefes políticos en la región del noroeste de la provincia, una situación particular ocurría en Cruz del Eje. A partir de la década de 1920, con el avance del radicalismo azul o antipersonalista en el departamento, la designación de esta autoridad departamental dividía las aguas entre los candidatos que el gobierno provincial proponía para la ocupación del cargo y aquellos considerados por la facción azul del Partido Radical. Tal fue el caso en 1920 con la renuncia del jefe político y el nombramiento provisorio del comisario de la localidad por parte del gobierno de Roca, que generó el repudio del sector azul presente en el departamento. ${ }^{37}$

Lo que parecía de absoluto control de los agentes intermedios de estado provincial en una región, considerada "de atraso económico" y de marcado arraigo conservador y clientelar, modificaba las reglas de elección de las autoridades departamentales en un territorio de la serranía cordobesa en donde el creciente avance del radicalismo suponía "negociar" los términos de la elección.

Por disposición, el jefe político no podía (como ningún otro empleado público) participar en "trabajos electorales", constituirse en depositario de las boletas de inscripción en ellos, ni "acaudillar gente para votar", orden que se reproducía periódicamente como actitud gubernamental de prescindencia.

36 "En el oeste", Los Principios, 25 de enero de 1914, p. 2, C5 y 6; "Jefatura de Calamuchita", La Nación, 4 de mayo de 1918, p. 10, C4; "Pidióse la renuncia al jefe político del departamento de Calamuchita. Campaña electoral”, La Nación, 20 de septiembre de 1928, p. 19, C3.

37 "La jefatura política de Cruz del Eje", La Voz del Interior, 8 de enero de 1920, p. 4, C3; "Jefatura de Cruz del Eje", La Voz del Interior, 18 de abril de 1920, p. 4, C5. 
Son numerosas las referencias de renuncias de los jefes políticos para realizar actividades electorales a favor de los candidatos conservadores. ${ }^{38}$

La convocatoria para concentraciones y mítines en los diversos espacios (rural y urbano) es un elemento ponderativo para evaluar la capacidad de movilización con la que contaban estos caudillos y quizás una de las actividades electorales que permite destacar su real intromisión entre los sectores populares.

Son abundantes las referencias sobre el número de ciudadanos presentes en las manifestaciones conservadoras y que la prensa, tanto independiente como partidista, detallaba con elocuencia: "El número de manifestantes no bajaba de 500 personas [...] Llegados los manifestantes al comité, fueron obsequiados con cervezas servidas personalmente por las señoritas. ${ }^{\prime 39} \mathrm{El}$ periódico Justicia, de inclinación católica y favorable al Partido Constitucional, señalaba en el marco de las elecciones nacionales de diputados en 1912 el número de participantes en la manifestación convocada por la tendencia católica del conservadurismo provincial. Si bien la cifra puede ser exagerada, no deja de ser llamativa la importancia que la prensa le asignaba a la ocupación del espacio público con numerosos manifestantes como parte de una estrategia de cooptación de electores: "El Partido ha dado anoche una elocuente prueba de sus prestigios en Córdoba. Con un día de propaganda ha reunido una columna de más de 5000 ciudadanos que han acudido al llamado con un entusiasmo emocionante." 40

La asistencia a los actos provee información sobre las responsabilidades que se tienen hacia un mediador (y las responsabilidades de este para con sus seguidores). El acto es un "ritual", en el sentido que Paige y Paige (1981) le dan

${ }^{38}$ Durante el periodo trabajado, la prensa nacional y provincial destacaban en cada coyuntura eleccionaria la renuncia de los jefes políticos y otros empleados del Estado. "Notas Políticas. El jefe político de Marcos Juárez", Los Principios, 30 de noviembre de 1912, p. 2, C5 y 6; "Situación electoral en Punilla", La Voz del Interior, 11 de enero de 1914, p. 5, C2 y 3; "Jefatura política de Totoral", La Voz del Interior, 25 de octubre de 1916, p. 3, C7; "El jefe político de Cruz del Eje", La Voz del Interior, 24 de enero de 1917, p. 4, C4; "Jefatura de Sobremonte", La Voz del Interior, 14 de marzo de 1918, p. 4, C3; "Jefatura de Cruz del Eje", La Voz del Interior, 18 de abril de 1918, p. 4, C5; "Jefatura de Río Seco", La Nación, 22 de mayo de 1918, p. 10, C6; "El jefe político de Río IV. Después de una investigación fracasada renuncia el cargo", La Voz del Interior, 17 de agosto de 1919, p. 4, C3; "Jefatura Política de Tercero Abajo", La Voz del Interior, 14 de octubre de 1919, p. 4, C5; "Jefaturas políticas de Cruz del Eje y Río 1", La Voz del Interior, 12 de febrero de 1921, p. 4, C7; "Pidióse la renuncia al jefe político del departamento de Calamuchita", La Nación, 20 de septiembre de 1928, p. 19, C3.

39 “Notas Políticas. Los trabajos políticos", La Voz del Interior, 13 de marzo de 1913, p. 4, C5.

40 "La gran manifestación de anoche", Justicia, 8 de abril de 1912, p. 3, C2-4, y p. 4, C1. 
al término: "una oportunidad para declarar las intenciones de los seguidores y los mediadores y para evaluar las intenciones de cada cual" (Auyero, 2001).

Sin embargo, la misma lógica política impuesta por la reforma electoral de 1912, que amplió los márgenes de negociación de los caudillos locales, implicó -para las fuerzas conservadores fundamentalmente- la incorporación de los líderes políticos departamentales, quienes tenían el control y el dominio de la población local. Por lo que las prácticas clientelares, como parte de una estrategia electoral, lejos de desaparecer se extendieron y consolidaron.

Algunas investigaciones que explican el impacto de la reforma sobre los conservadores manifiestan la exacerbación de las prácticas clientelísticas desplegadas por estos sectores. Uno de estos estudios es el de María Dolores Béjar, quien además realiza un análisis sobre la función de los caudillos en las prácticas electorales de los conservadores y como intermediarios entre la sociedad y el Estado, destacando el aumento de su poder tras la reforma (Béjar, 2002, p. 33). Por su parte, Julio César Melón Pirro, para la ciudad de Buenos Aires, demostró que la reforma fue una ventaja para la preservación y aún más la ampliación de los márgenes de poder de los caudillos, ya que las posibilidades de movilización de los mismos fueron mayores por la obligatoriedad del voto (Melón Pirro, 1994, pp. 30-45).

En el juego clientelar hay una suerte de rito de amplia difusión en la campaña: el asado con cuero, sustituto del banquete del espacio urbano y un momento más de los "trabajos electorales". Los bailes y asados campestres para la población de la zona de Punilla se transformaron en eventos que permitían, además de la cooptación electoral, fortalecer el vínculo líder-seguidor: "en La Falda, los candidatos demócratas para mantener el ambiente caldeado, mientras se desarrollaba un programa de amplia oratoria a cargo de los delegados y algunos comedidos, se hizo entrever a la concurrencia la interesante perspectiva de un suculento asado con cuero, con acompañamiento de empanadas". ${ }^{41}$

A través de los "caudillos departamentales", los dirigentes políticos lograban comprender y asimilar la realidad social de cada región y en función de eso adaptar sus estrategias. Inmiscuirse en las costumbres e idiosincrasia de los grupos electorales fue una necesidad para los dirigentes a la hora de ganar elecciones. Una vez comprendida esta realidad se abocaban a realizar

41 "Más allá de la sierra", Los Principios, 29 de enero de 1914, p. 2, C7, y p. 3, C1-3; "Las elecciones en Totoral”, La Voz del Interior, 31 de marzo de 1914, p. 2, C6 y 7. 
actividades y eventos que despertaran no sólo el interés de la gente, sino la identificación de los candidatos con la población. Cuando se lograba esta identificación era posible convencer al votante. ${ }^{42}$

Las clases propietarias contaban con suficientes recursos para incidir en el electorado. En las elecciones para diputados nacionales de abril de 1915, el señor Ferrer había pagado al erario municipal en Río IV 120 peones que previamente entregaron sus libretas cívicas en garantía del compromiso contraído de votar a favor del candidato conservador Félix Sarría. ${ }^{43}$

No obstante, teniendo en cuenta que la reforma de 1912 amplió los márgenes de negociación de los ciudadanos al garantizar el secreto del sufragio e incrementar exponencialmente su número, se pusieron importantes límites al control de los caudillos sobre la población local. Eran recurrentes las denuncias de la ciudadanía dirigidas a las prácticas de coacción, de violencia y al uso de las prácticas clientelares desplegadas por estos sujetos durante las contiendas electorales. ${ }^{44}$

Por otro lado, el jefe político poseía un amplio capital relacional acumulado que coadyuvaba en la configuración de una extensa red de relaciones producto de interacciones regulares; estas si bien normalmente son inauguradas por un "favor fundacional", deben ser cultivadas y practicadas de manera constante. Invitado por el jefe político de Punilla, el por entonces gobernador

${ }^{42}$ No olvidemos que, aunque la utilización de la violencia, la coacción y el clientelismo se mantuvieron y hasta adoptaron modalidades más sutiles -como en el caso de la organización de mítines por garitos-, la práctica de convencimiento/persuasión del ciudadano comenzó a utilizarse frecuentemente por los candidatos al momento de cooptar el voto de la población.

43 "La campaña de Sarría”, Los Principios, 15 de octubre de 1915, p. 3, C5.

44 "Denuncias contra los caudillos", Los Principios, 6 de noviembre de 1912, p. 2, C6; "Denuncia de los ciudadanos", Los Principios, 8 de noviembre de 1912, p. 3, C3 y 4; "Prácticas de coacción de los caudillos", Los Principios, 31 de octubre de 1912, p. 2, C5 y 6; "El acaparamiento de libretas", La Voz del Interior, 29 de marzo de 1916, p. 3, C4; "Denuncia del Dr. Núñez”, La Voz del Interior, 28 de septiembre de 1916, p. 4, C3; "Las elecciones de senadores. Denuncias contra autoridades", La Prensa, 1 de octubre de 1916, p. 14, C2 y 3; "Las denuncias opositoras", La Voz del Interior, 28 de marzo de 1918, p. 4, C3; "Las denuncias cordistas", La Voz del Interior, 26 de febrero de 1920, p. 4, C2 y 3; "Denuncia contra las autoridades", La Voz del Interior, 13 de marzo de 1921, p. 6, C3 y 4; "Las elecciones provinciales. Denuncia de un abuso policial", La Voz del Interior, 28 de marzo de 1922, p. 7, C3 y 4; "Córdoba. Denuncia de un candidato. Los ferrocarriles electorales", La Prensa, 1 de marzo de 1924, p. 11, C6; "Las arbitrariedades de las policías demócratas", La Voz del Interior, 22 de marzo de 1925, p. 8, C3; "Un caudillejo demócrata que procede a su antojo", La Voz del Interior, 28 de julio de 1927, p. 13, C3 y 4; "La denuncia sobre secuestro de libretas", La Voz del Interior, 2 de marzo de 1930, p. 3, C6 y 7; "Secuestro de libretas cívicas”, La Prensa, 24 de febrero de 1930, p. 12, C3. 
de la provincia Ramón J. Cárcano fue informado detalladamente de los problemas que padecía el departamento, fundamentalmente los edificios escolares, la escasez de recursos policiales, entre otras dificultades. ${ }^{45}$

Por su parte, el jefe político de Pocho destacaba en las memorias anuales, la situación de aislamiento en la que se encontraba este departamento y las consecuencias económicas de esta situación. Al respecto señalaba: "Este departamento tan desventajosamente colocado por su situación geográfica comparado con el resto de la Provincia, tiene un problema en su vialidad; sin la influencia de ningún Ferrocarril que transporte sus productos sólo quedará resuelto este problema, con la construcción de caminos que den acceso a las plazas de consumo." ${ }^{46}$

Asimismo, como problemática presente en todos los departamentos del noroeste de la provincia, el agua potable era un recurso escaso que requería de una importante inversión presupuestaria para su desarrollo; sin embargo, y a pesar de los reiterados pedidos de los jefes políticos, el departamento carecía de infraestructura necesaria para garantizar el abastecimiento del recurso hídrico. En la misma memoria sobresalía este inconveniente: "a pesar de los esfuerzos realizados, no se ha conseguido dar con agua, se espera que con el nuevo proyecto de perforación que ya está en licitación se consiga resolver este problema de vital importancia para esta población" ${ }^{47} \mathrm{La}$ misma situación se repetía en la localidad de Quilino (departamento Ischilín), cuyas solicitudes de intervención del poder ejecutivo provincial eran permanentes. ${ }^{48}$

Esta práctica de mediación se reproducía también en los departamentos de mayor urbanización. En la localidad de San Francisco, el jefe político de San Justo manifestaba al ministro de gobierno la necesidad de ampliar el presupuesto para mejorar las condiciones edilicias del Departamento de Obras Públicas. ${ }^{49}$ Unos meses más tarde, la misma jefatura política solicitaba la construcción de un edificio escolar en una localidad del departamento y señalaba los problemas de las instituciones escolares, que carecían de espacio suficiente e higiene necesaria para los escolares. ${ }^{50}$

\footnotetext{
45 “Gira del ministro de Gobierno de Punilla”, La Voz del Interior, 20 de enero de 1914, p. 2, C5.

6 Jefaturas Políticas. 1927. Tomo 42, f. 408. AHPC, Argentina.

${ }^{47}$ Jefaturas Políticas. 1927. Fondo Gobierno. Tomo 42, f. 408. AHPC, Argentina.

${ }^{48}$ Jefaturas Políticas. 1927. Fondo Gobierno. Tomo 42, f. 408. AHPC, Argentina.

49 "Jefatura Política de San Justo", Los Principios, 27 de febrero de 1912, p. 3, C1.

Jefaturas Políticas. 1912. Fondo Gobierno. Tomo 6, f. 519. AHPC, Argentina.
} 
En los departamentos del este y sureste de la provincia la competencia electoral era aún mucho más reñida entre las dos grandes fuerzas políticas mayoritarias, por lo que tanto radicales como conservadores diseñaban estrategias de intervención para resolver los problemas materiales de estas localidades, prácticas que se incrementaban durante los periodos electorales.

El 11 de marzo de 1928 tuvieron lugar las elecciones provinciales para elegir gobernador y vicegobernador de la provincia de Córdoba, y el triunfo correspondió, por una diferencia de diez puntos, a los candidatos radicales Enrique Martínez y Antonio Ceballos. Ante un triunfo prominente en la mayoría de los departamentos de la provincia, los demócratas lograron triunfar en Sobremonte, San Alberto, Tulumba e Ischilín. Quizá como una de las consecuencias políticas más inmediatas de este avance radical, fue la renuncia de aquellos jefes políticos filodemócratas como autoridades departamentales. En este sentido, en mayo de 1928, presentaban su renuncia varios jefes políticos que manifestaban su filiación al radicalismo. ${ }^{51}$

Un último hecho a destacar es el manejo que el jefe político tenía de toda la estructura policial de la respectiva jurisdicción, lo que importa concentrar en ellos (en términos de Bourdieu) el "capital de fuerza policía", uno de los componentes de la construcción y consolidación del poder. Al mismo tiempo, en tanto "agentes dependientes directos del ejecutivo provincial, brindan a este el control de la campaña $y$, por consiguiente, se transforman en un engranaje importantísimo de la maquinaria electoral" (Pavoni, 2000, p. 120) que garantiza el triunfo de las candidaturas oficiales $u$ oficialistas, la conservación del ejercicio del poder por los sectores tradicionales y el mantenimiento de las relaciones de fuerza existentes.

Era fácil reconocer a "conspicuos dirigentes electorales", hombres que estaban a la cabeza de las huestes de votantes, como el comisario, los empleados municipales o provinciales o los jefes de policía (Sábato, 1998, pp. 128135): "El comisario Alejandro Bustamante recorre la campaña invitando a los ciudadanos a concurrir a los comités carcanistas. Jerónimo Arce, empleado nacional, hace descarada propaganda a favor del Dr. Cárcano." ${ }^{52}$

${ }^{51}$ Jefaturas Políticas. 1928. Fondo Gobierno. Tomo 12, f. 560; Jefaturas Políticas. 1928. Fondo Gobierno, Tomo 12, f. 567; Jefaturas Políticas. 1918. Fondo Gobierno. Tomo 13, f. 79; Jefaturas Políticas. 1928. Fondo Gobierno. Tomo 13, f. 89. AHPC, Argentina.

52 "Departamento Ischilín”, La Voz del Interior, 9 de octubre de 1912, p. 5, C4; “Las crónicas periodísticas ilustran detalladamente el uso de la violencia en las localidades del Norte de la Provincia, para el caso de Totoral: Departamento Totoral", La Voz del Interior, 22 de marzo de 
El monopolio de la violencia física era disputado por el poder ejecutivo, por el estado provincial que utilizaba la fuerza policial como uno de los recursos electorales fundamentales para intimidar por medio del uso de la coerción a los partidos políticos opositores o a los potenciales votantes. La alternancia de los gobernadores del Partido Demócrata en el ejercicio de la función ejecutiva no modificó esta situación.

Si bien la violencia y la coacción durante las contiendas electorales eran sucesos que se repetían en los diferentes departamentos, quisiera referirme concretamente al caso de La Cumbre durante la elección provincial de abril de 1920, dada la amalgama de prácticas puestas en escena durante la campaña electoral. Con el uso del tradicional asado con cuero para cooptar a los votantes a través de estrategias que recurrían a la idiosincrasia local, el evento había terminado en malos términos cuando "un grupo exaltado, la mayoría en completo estado de ebriedad, se apersonó en el municipio dando gritos contra la autoridad" ${ }^{53}$ Una situación similar se repetía en Villa Cura Brochero (departamento San Alberto), cuando durante la elección para senador provincial de marzo de 1918, el jefe político acompañaba al candidato demócrata en sus respectivas giras electorales que, a pesar de la novedad que implicaba respecto al periodo precedente, favoreciendo la intromisión de los candidatos de la capital en el interior cordobés por medio de estas figuras políticas intermedias, continuaban reproduciendo las prácticas anacrónicas de coacción y violencia hacia el elector: "Agentes del oficialismo secuestran libretas de nuestros correligionarios y públicamente declaran ganarán elección a fuerza de machete." ${ }^{54}$

\section{CONSIDERACIONES FINALES}

El presente artículo tuvo como objetivo principal analizar, en el marco del proceso de democratización política operada en la provincia de Córdoba a raíz de la aplicación de la ley Sáenz Peña, las prácticas, estrategias y mecanismos de movilización y reclutamiento electoral por parte de los jefes políticos, como instrumento clave de penetración del Partido Demócrata en el

1914, p. 2, C4; "Los mártires del Señor Cárcano, 9 de octubre de 1912" en "Cruz del Eje”, La Voz del Interior, 29 de septiembre de 1913, p. 5, C3; "Las policías de Campaña. Síntomas elocuentes", La Voz del Interior, 13 de octubre de 1913, p. 4, C2.

${ }_{53}$ Jefaturas Políticas. 1920. Fondo Gobierno. Tomo 6, f. 519. AHPC, Argentina.

54 “La situación en San Alberto", La Voz del Interior, 26 de marzo de 1918, p. 4, C2 y 3. 
interior provincial. Si bien los jefes políticos no fueron los únicos actores de este proceso, no podemos dejar de reconocer que su fuerte vinculación con la población departamental -a través de las múltiples y diversas funciones que cumplían-coadyuvó en este proceso de articulación de las demandas locales y de acercamiento a las necesidades materiales de los pueblos y ciudades, incrementando en tiempos electorales el caudal de votantes para los partidos políticos, en este caso, el Partido Demócrata.

Desde la creación de las jefaturas políticas en 1870, se convirtieron en agentes directos del poder ejecutivo provincial y disputaron a los municipios el control y dominio del interior. Los recursos económicos (para ser jefe político era necesario contar con cierto capital material) y el control de las fuerzas policiales departamentales permitía a estos agentes estatales movilizar un número importante de ciudadanos para las campañas electorales. De este modo, las prácticas clientelares y los mecanismos de coacción y violencia hacia los grupos opositores fueron las estrategias más utilizadas por los jefes políticos, prácticas que no se limitaban a intimidar a los votantes y los partidos políticos opositores, sino además era una forma de ejercer y legitimar su poder a escala departamental.

Como parte de un proceso de transformación del comportamiento electoral del conservadurismo cordobés, los actos políticos, las movilizaciones, las manifestaciones y las conferencias públicas -que tenían el propósito de mostrar el potencial convocante del Partido Demócrata- fueron las actividades de campaña que organizaban estos caudillos en cooperación con los comités departamentales.

Dicha capacidad de movilización y reclutamiento de los electorados respondía, a su vez, a la articulación de las demandas sociales más inmediatas de las localidades del interior. Los jefes políticos elevaban anualmente memorias acerca del funcionamiento de los departamentos, los avances realizados durante su gestión y las principales problemáticas que atravesaban las poblaciones. En este sentido, se convirtieron en mediadores entre la dirigencia política capitalina y la ciudadanía local y tejieron redes de relaciones entre diversos actores políticos con el fin de resolver los problemas materiales del interior.

La construcción de caminos, escuelas, hospitales, la instalación de un servicio de agua potable, alumbrado y la realización de diversas obras públicas formaban parte de las funciones atribuidas a los jefes políticos que, en estrecha vinculación con la sociedad, intervenían -a través de su poder- en las instancias superiores del Estado provincial. Estos avances en materia de 
obra pública formaban parte del discurso de campaña de los dirigentes políticos del Partido Demócrata (aunque también los radicales recurrían a estas prácticas), y se resolvían concretamente a través de la mediación de estas autoridades departamentales.

A diferencia de los departamentos del este y sureste de la provincia, donde la competencia reñida con el radicalismo impedía que el Partido Demócrata tuviese el control de los electorados, en los departamentos del oeste (sobre todo en la región de Traslasierra) y en menor medida los del noroeste, los demócratas lograban triunfar en las elecciones.

En síntesis, los jefes políticos fueron agentes estatales funcionales al poder político central, y si bien eran designados y depuestos por el gobierno provincial, contaban con un amplio margen de negociación que les permitía, en el marco de las campañas electorales, aportar -a través de una diversidad de recursos como el capital económico, relacional, la resolución de problemáticas materiales y la vinculación directa con los ciudadanos- un amplio caudal de votos para que los partidos en general, y el Demócrata en particular, lograran importantes resultados electorales.

\section{LISTA DE REFERENCIAS}

Auyero, J. (2001). La política de los pobres. Las prácticas clientelistas del peronismo. Buenos Aires: Manantial.

Béjar, M. D. (2002). Los conservadores: un partido desde el gobierno. Estudios Sociales, 22-23.

Bonaudo, M. (2003). Las élites santafesinas entre el control y las garantías: el espacio de la jefatura política. En H. Sábato y A. Lettieri (comps.), La vida política en la Argentina del siglo XIX. Armas, votos y voces. Buenos Aires: Fondo de Cultura Económica.

Cucchi, L. (2015). Antagonismo, legitimidad y poder político en Córdoba, 1870-1890. Buenos Aires: Universidad Nacional del Sur.

Cuesta Figueroa, M. de la (1977). El jefe político en la campaña de Salta. Revista de Historia del Derecho, 5, 43-73.

Delgado Aguilar, F. J. (2004). Orígenes e instalación del sistema de jefaturas políticas en México 1876-1824. Estudios de Historia Moderna y Contemporánea de México, 28, 5-29. Recuperado de http://www.scielo.org.mx/scielo.php?script=sci_arttext\&pi$\mathrm{d}=$ S0185-26202004000200005\&lng=es\&tlng=es 
Falcón, R. (1992). Jefes políticos y rebeliones campesinas: Uso y abuso del poder en el Estado de México. En J. Rodríguez (comp.), Patterns of contention in Mexican history. Willmington: SR Books.

Falcón, R. (1998). Los jefes políticos: eslabones del poder. En M. Miño Grijalva (ed.), Historia general del Estado de México. República restaurada y porfiriato. Gobierno de México: Estado de México/El Colegio Mexiquense.

Falcón, R. (2015). El jefe político. Un dominio negociado en el mundo rural del Estado de México, 1856-1911. México: El Colegio de México.

Giannone L. (2014). El conservadurismo cordobés en los primeros tiempos de la aplicación de la ley Sáenz Peña (1912-1916). (Tesis de licenciatura). Facultad de Filosofía y Humanidades-Universidad Católica de Córdoba, Argentina.

Giannone, L. (2018). El acceso diferencial a los recursos: el agua potable en el noroeste de Córdoba, Argentina (1912-1930). Folia Histórica del Nordeste, 33, 91-112. DoI: http://dx.doi.org/10.30972/fhn.0333552

Mecham, J. Lloyd (1986). El jefe político en México. Secuencia, 4, 143-156. DoI: https:// doi.org/10.18234/secuencia.v0i04.131

Melón Pirro, J. C. (1994). La ley de Sáenz Peña de Ugarte, o el éxito de la reforma conservadora en la provincia de Buenos Aires. En F. Devoto y M. Ferrari (comps.), La construcción de las democracias Rioplatenses: proyectos institucionales y prácticas políticas 1900-1930. Buenos Aires: Biblos.

Paige, K. E. y Paige, J. M. (1981), The politics of reproductive ritual, University of California Press.

Pavoni, N. (2000). Las jefaturas y su incidencia en el clientelismo rural: Córdoba, 18701890. Cuadernos de Historia. Serie Economía y Sociedad, 3, 113-167. Recuperado de https://revistas.unc.edu.ar/index.php/cuadernosdehistoriaeys/article/view/9864

Pavoni, N. (2016). Facciones, partidos y clientelismo político en la Córdoba de entre siglos, 1890-1912. Córdoba: Universidad Nacional de Córdoba.

Sábato, H. (1998). La política en las calles. Entre el voto y la movilización, Buenos Aires, 1862-1880. Buenos Aires: Sudamericana.

Salazar Vilchis, E. (2012). El jefe político. Transformaciones en la administración pública del Estado de México e injerencia en el contingente de sangre, 1867-1876. Contribuciones desde Coatepec, 22, 69-95. Recuperado de https://www.redalyc.org/ articulo.oa?id=28123934005

Vidal, G. y Ferrari, M. (2000). Estrategias de reclutamiento y movilización de las élites políticas cordobesas, 1912-1930. Recuperado de www.fec.tchc.br/sistefee/ clown/oad/jornadas/1/S1/a4.pdf 
Vilar, P. (1976). Crecimiento económico y análisis histórico. En P. Vilar (comp.), Crecimiento y desarrollo. Barcelona: Ariel.

Wolf, E. (1990). Relaciones de parentesco, de amistad y de patronazgo en las sociedades complejas. En Antropología social de las sociedades complejas (pp. 19-39). (Clásicos y Contemporáneos en Antropología). México: CiesAs/uAm/UiA.

Yangilevich, M. (2018). Prefecturas, comisarías de campaña y construcción estatal en la Provincia de Buenos Aires (Argentina) a mediados del siglo xIx. Secuencia, 102, 70-99. DoI: https://doi.org/10.18234/secuencia.v0i102.1359

\section{OTRAS FUENTES}

Archivos

AHPC Archivo Histórico de la Provincia de Córdoba, Argentina.

\section{Periódicos}

El País, Córdoba (1912-1930).

Justicia, Córdoba (abril-junio de 1912).

La Voz del Interior, Córdoba (1912-1930).

La Nación, Buenos Aires (1912-1930).

La Prensa, Buenos Aires (1912-1930).

Los Principios, Córdoba (1912-1930). 